\title{
Frequency, Diversity, and Activity of 2,4-Diacetylphloroglucinol-Producing Fluorescent Pseudomonas spp. in Dutch Take-all Decline Soils
}

\author{
Jorge T. de Souza, David M. Weller, and Jos M. Raaijmakers
}

First and third authors: Wageningen University, Laboratory of Phytopathology, Binnenhaven 5, P.O. Box 8025, 6709 PG, Wageningen, The Netherlands; and second author: Root Disease and Biological Control Research Unit, U.S. Department of Agriculture-Agricultural Research Service, Washington State University, Pullman 99164.

Accepted for publication 12 August 2002.

\begin{abstract}
de Souza, J. T., Weller, D. M., and Raaijmakers, J. M. 2003. Frequency, diversity, and activity of 2,4-diacetylphloroglucinol-producing fluorescent Pseudomonas spp. in Dutch take-all decline soils. Phytopathology 93: 54-63.

Natural suppressiveness of soils to take-all disease of wheat, referred to as take-all decline (TAD), occurs worldwide. It has been postulated that different microbial genera and mechanisms are responsible for TAD in soils from different geographical regions. In growth chamber experiments, we demonstrated that fluorescent Pseudomonas spp. that produce the antibiotic 2,4-diacetylphloroglucinol (2,4-DAPG) play a key role in the natural suppressiveness of two Dutch TAD soils. First, 2,4-DAPG-producing fluorescent Pseudomonas spp. were present on roots of wheat grown in both of the TAD soils at densities at or above the threshold density required to control take-all of wheat; in a complementary take-all

typic group found in the Dutch TAD soils, into the take-all conducive soil at population densities similar to the densities of indigenous 2,4-DAPG producers found in TAD soils provided control of take-all similar to that observed in the TAD soil. Third, a mutant of strain SSB17 deficient in 2,4-DAPG production was not able to control take-all of wheat, indicating that 2,4-DAPG is a key determinant in take-all suppression. These results show that in addition to the physicochemically different TAD soils from Washington State, 2,4-DAPG-producing fluorescent Pseudomonas spp. are also a key component of the natural suppressiveness found in Dutch TAD soils. Furthermore, it is the first time since the initial studies of Gerlagh (1968) that at least part of the mechanisms and microorganisms that operate in Dutch TAD soils are identified. Although quantitatively similar, the genotypic composition of 2,4-DAPG-producing Pseudomonas spp. varied between the Dutch TAD soils and the TAD soils from Washington State.
\end{abstract} conducive soil, population densities of 2,4-DAPG-producing Pseudomonas spp. were below this threshold level. Second, introduction of 2,4DAPG-producing strain SSB17, a representative of the dominant geno-
Additional keywords: microbial ecology, rhizosphere competence, suppressive soils.
Take-all, caused by the fungus Gaeumannomyces graminis var. tritici, is an important root disease of wheat worldwide (2). Although wheat is particularly susceptible to the take-all fungus, many other Gramineae can be infected (34). Take-all decline (TAD) is defined as the spontaneous decrease in the incidence and severity of take-all that occurs with monoculture of wheat or other susceptible host crops after one or more severe outbreaks of the disease $(10,19,34)$. Soils in the state of TAD are naturally suppressive to the take-all fungus. The biological basis of the specific suppression associated with TAD has been demonstrated in a series of experiments: suppressiveness is eliminated by treating the soil with moist heat (pasteurization, $60^{\circ} \mathrm{C}$ for $30 \mathrm{~min}$ ), methyl bromide, or chloropicrin, and is transferable by adding small amounts of TAD soil to raw conducive, fumigated or pasteurized soil (10,11, 28). The mechanisms responsible for TAD involve microbiological changes in the bulk soil or rhizosphere environment resulting in suppression of the pathogen (9). Repeated introduction of $G$. graminis var. tritici into soil also induces suppression of take-all $(17,42,45)$, but the relation of this form of suppressiveness to that of TAD is not clear.

The occurrence of TAD throughout the world is remarkable in view of the broad range of soil types, climates, and agronomic conditions under which wheat is cultivated (34). Field studies

Corresponding author: J. M. Raaijmakers; E-mail address: Jos.Raaijmakers@wur.nl

Publication no. P-2002-1031-01R

(C) 2003 The American Phytopathological Society have clearly indicated that the development of TAD follows a consistent pattern everywhere requiring the presence of three components: monoculture of a take-all susceptible host, the presence of $G$. graminis var. tritici, and at least one occurrence of severe disease. Factors such as soil type and previous cropping history seem only to modulate the extent and speed of development of TAD (34). Previous work on TAD has suggested that different microbial genera and mechanisms are responsible for suppressiveness in soils from different geographical regions. First, TAD develops in multiple agroecosystems $(6,34)$. Second, the length of time for TAD to develop varies among fields and the crop grown in monoculture (34). Finally, antagonists from many different taxonomic groups have been isolated from TAD soils and, when introduced into take-all conducive soils, provide a certain level of control of take-all $(1,13,19,41,44)$. Despite the wide range of microorganisms implicated in TAD, however, several of them do not fit one or more of the biological properties of TAD (9). For example, the sensitivity of the TAD factors to pasteurization with moist heat $\left(60^{\circ} \mathrm{C}, 30 \mathrm{~min}\right)$ rules out the involvement of heat-resistant sporeforming bacteria like Bacillus spp. and probably also actinomycetes (10).

Among the antagonistic bacteria, the fluorescent Pseudomonas spp. have been implicated in TAD soils throughout the world $(11,28,32,36,38,41)$. Characteristics that suggest involvement of pseudomonads in TAD include the following: they are well adapted to the rhizosphere environment and produce a variety of secondary metabolites, including antibiotics and siderophores, that inhibit the growth of $G$. graminis var. tritici $(38,41)$, their population densities 
increase considerably on roots with take-all lesions $(4,6,8,32,36)$, and their populations are substantially diminished by soil pasteurization, which also eliminates specific suppression $(10,28)$. Recent studies demonstrated that fluorescent Pseudomonas spp. producing the antibiotic 2,4-diacetylphloroglucinol (2,4-DAPG) play a key role in the suppressiveness of TAD soils in Washington State $(27,28,30)$. Using specific primers and probes directed against sequences within the biosynthetic locus of 2,4-DAPG have clearly indicated that fluorescent Pseudomonas spp. producing this antifungal metabolite are highly enriched in TAD soils from Washington State (30). Substantial reduction of populations of 2,4-DAPG producers resulted in loss of suppressiveness (28). When a 2,4-DAPG-producing strain was introduced via seed treatment into a take-all conducive soil, it provided control of take-all of wheat to levels similar to that obtained in the complementary TAD soil (28).

One key question has been whether 2,4-DAPG-producing Pseudomonas spp. also play a key role in the specific suppression found in TAD soils from other geographical regions. Pseudomonas spp. harboring phlD (phlD+), one of the key genes in the biosynthesis of 2,4-DAPG, were found on roots of wheat grown in other soils with a history of wheat monoculture (24), however, the level of take-all suppressiveness of these soils and the role of 2,4-DAPG in take-all suppression were not addressed. In this study, we determined the frequency, diversity, and activity of 2,4-DAPGproducing Pseudomonas spp. found in Dutch polder soils with a history of wheat monoculture. Dutch polder soils were among the first TAD soils reported (17), however, the exact mechanisms operating in these soils have not been elucidated. Phenotypic and genotypic analyses were performed to characterize 2,4-DAPGproducing Pseudomonas isolates obtained from Dutch soils. The biocontrol efficacy and rhizosphere competence of Pseudomonas fluorescens SSB17, a representative of the major genotypic group of 2,4-DAPG-producers found in a Dutch soil, were compared with that of Q8r1-96, a representative of the major genotypic group of 2,4-DAPG-producers found in TAD soils from Washington State (29). The role of 2,4-DAPG in control of take-all and in rhizosphere competence was determined for both strains by generating mutants deficient in 2,4-DAPG production. Finally, we determined whether populations of 2,4-DAPG-producing Pseudomonas spp. are specifically enriched upon infection of wheat roots by the take-all fungus.

\section{MATERIALS AND METHODS}

Microorganisms. Naturally occurring populations of fluorescent Pseudomonas spp. were isolated from the wheat rhizosphere on King's medium B (KMB) agar supplemented with chloramphenicol $\left(13 \mu \mathrm{g} \mathrm{ml}^{-1}\right)$, ampicillin $\left(40 \mu \mathrm{g} \mathrm{ml}^{-1}\right)$, and cycloheximide $\left(100 \mu \mathrm{g} \mathrm{m}^{-1}\right)\left[\mathrm{KMB}^{+}\right](35)$. All Pseudomonas strains described in this study, including SSB17 (this study), Q8r1-96 (29), Pf5 and CHA0 (21), were grown on KMB. Spontaneous rifampicin-resistant derivatives of SSB17 and Q8r1-96 were selected on KMB supplemented with rifampicin $\left(100 \mu \mathrm{g} \mathrm{ml}^{-1}\right)$ and included in the biological control and rhizosphere competence assays. In these bioassays, background levels of indigenous, rifampicin-resistant microorganisms were below detection limit. Strains 9H4 and 4C5 are 2,4-DAPG-deficient mutants derived from strain SSB17 and
Q8r1-96, respectively. 2,4-DAPG-deficient mutants are resistant to rifampicin $\left(100 \mu \mathrm{g} \mathrm{ml}^{-1}\right)$ and kanamycin $\left(100 \mu \mathrm{g} \mathrm{ml}^{-1}\right)$. Escherichia coli strain S17 $\lambda$ pir was obtained from L. S. Thomashow (USDA-ARS, WA) and contained the mini-Tn5lacZ element in plasmid pUT (14). S17 $\lambda$ pir was grown in liquid Luria Bertani (LB) amended with kanamycin $\left(25 \mu \mathrm{g} \mathrm{ml}^{-1}\right)$. All bacterial strains were stored at $-80^{\circ} \mathrm{C}$ in $\mathrm{LB}$ or $\mathrm{KMB}$ broth supplemented with $40 \%$ (vol/vol) glycerol.

Strain R3-111a-1 of G. graminis var. tritici (the causal agent of take-all) was originally isolated from wheat grown in a soil near Moses Lake, Washington State. Strain C-1 of Rhizoctonia solani anastomosis group (AG)-8 (the causal agent of Rhizoctonia root rot) was obtained from the collection maintained by the USDAARS, Pullman, WA. Strain CBS 219.65 of Pythium ultimum var. sporangiiferum (the causal agent of Pythium root rot) was obtained from the Dutch collection of microorganisms (CBS, Baarn, The Netherlands). G. graminis var. tritici, R. solani, and Pythium ultimum var. sporangiiferum were routinely grown on potato dextrose agar (PDA; Oxoid Ltd., Basingstoke, Hampshire, England). Mycelial plugs were immersed in sterile mineral oil and stored at $15^{\circ} \mathrm{C}$.

Soils. Soils CB, SV, and SSB were obtained in December 1997, 1999, and 2001 from agricultural polder fields in Woensdrecht, The Netherlands. Woensdrecht is located in the southwest of the Netherlands, $10 \mathrm{~km}$ from the city Bergen op Zoom. In 1997, the SV and SSB soil had been continuously cropped to wheat for 14 and 27 years, respectively; the $\mathrm{CB}$ soil was grown to wheat and sugarbeet in a 1:2-year rotation scheme. Soils were collected from the top $50 \mathrm{~cm}$ of the soil profile, air dried for a week, and passed through a $0.5-\mathrm{cm}$ mesh screen prior to use. Chemical and physical properties of the soils used in this study are listed in Table 1.

Natural suppressiveness of soils to $G$. graminis var. tritici and $\boldsymbol{R}$. solani. Soils were amended with 0.1 to $0.4 \%$ (wt/wt) of an oat grain inoculum of $G$. graminis var. tritici strain R3-111a-1 (particle size 0.25 to $0.50 \mathrm{~mm}$ ) (28); sterilized oat grain inoculum was used as a control. The inoculum used in the experiments was obtained from different batches and therefore the concentration varied between experiments to ensure similar disease levels. Wheat seeds (cv. Bussard) were sown in PVC pots $(8 \mathrm{~cm}$ high, $7 \mathrm{~cm}$ wide) containing $200 \mathrm{~g}$ of soil and covered with a 1-cm layer of soil without inoculum. Plants were grown for 4 weeks in climate chambers at $15^{\circ} \mathrm{C}$ with a 12 -h photoperiod. Twice a week, plants received $50 \mathrm{ml}$ of 1/3-strength Hoagland's solution (macroelements only). Each treatment had five replicates with approximately 12 plants per replicate. Eight randomly selected plants were harvested, their root systems washed and the severity of take-all determined on a 0 -to- 8 scale, where 0 indicates no disease and 8 indicates a dead plant (28). Similar to assays performed with $G$. graminis var. tritici, suppressiveness of the soils to $R$. solani was assessed by introducing $0.5 \%$ (wt/wt) of a whole millet grain inoculum of $R$. solani AG-8 3 days prior to planting the wheat seeds; sterilized millet grain was used as a control. To assess the level of suppressiveness to $R$. solani infections, roots of eight randomly selected plants were harvested and washed, and root dry was weight determined. From each replicate, three to four randomly selected plants were collected for isolation of naturally occurring pseudomonads from the rhizosphere.

TABLE 1. Cropping history and physicochemical properties of the soils used in this study

\begin{tabular}{|c|c|c|c|c|c|c|c|c|c|c|c|c|}
\hline \multirow[b]{2}{*}{ Soil } & \multirow[b]{2}{*}{ Cropping history } & \multirow{2}{*}{$\begin{array}{l}\text { Wheat } \\
\text { cultivar }\end{array}$} & \multirow[b]{2}{*}{$\mathrm{pH}^{\mathrm{y}}$} & \multicolumn{5}{|c|}{ Content ( $\mu$ g per $g$ of soil) } & \multicolumn{4}{|c|}{ Content $(\%)$} \\
\hline & & & & $\mathrm{NO}_{3}-\mathrm{N}$ & $\mathrm{NH}_{4}-\mathrm{N}$ & $\mathrm{Na}$ & $\mathrm{P}$ & $\mathrm{K}$ & $\mathrm{OM}^{\mathrm{z}}$ & Sand & Silt & Clay \\
\hline $\mathrm{CB}$ & Rotation wheat/sugar beet & Bussard & 7.6 & 3 & 2 & 14 & 1 & 74 & 4.4 & 49 & 12 & 27 \\
\hline SV & 14 years continuous wheat & Monopol & 7.4 & 4 & 2 & 10 & 2 & 74 & 4.4 & 52 & 9 & 27 \\
\hline SSB & 27 years continuous wheat & Bussard & 7.5 & 3 & 2 & 9 & 2 & 89 & 4.4 & 50 & 10 & 28 \\
\hline
\end{tabular}

${ }^{y} \mathrm{pH}$ was determined after extraction with $\mathrm{CaCl}_{2}$.

${ }^{\mathrm{z}}$ Organic matter. 
Isolation and enumeration of phlD+ fluorescent Pseudomonas spp. After 4 weeks of plant growth, three to four plants of each replicate were harvested and loosely adhering soil was removed from the root system. Naturally occurring fluorescent Pseudomonas spp. were isolated from uninfected wheat roots and roots infected by $G$. graminis var. tritici or $R$. solani. From the infected roots, both nonlesioned and lesioned root sections were selected. Root samples of 0.2 to $1 \mathrm{~g}$ fresh weight were vortexed for $1 \mathrm{~min}$ and sonicated for $1 \mathrm{~min}$ in an ultrasonic cleaner (Bransonic 12; Branson Ultrasonics Corp., Geneva, Switzerland). Root suspensions were dilution plated onto $\mathrm{KMB}^{+}$and incubated at $25^{\circ} \mathrm{C}$ for $48 \mathrm{~h}$. Population densities of phlD+ Pseudomonas spp., a key gene in the biosynthesis of 2,4-DAPG, were determined by colony hybridization followed by polymerase chain reaction (PCR) (27). phlD+ colonies were purified and stored at $-80^{\circ} \mathrm{C}$ for further analyses.

Random amplified polymorphic DNA analysis. Random amplified polymorphic DNA (RAPD) analysis of phlD+ isolates was performed with primers M13, M12, and D7. These primers were selected by Keel et al. (21) among 64 other random primers based on the distinct and consistent banding patterns of the polymorphic markers produced. PCR was carried out in a $25-\mu \mathrm{l}$ reaction mixture as described previously (30). PCR amplifications were carried out in a thermocycler (PTC-200; MJ Research Inc., Watertown, MA). Samples (10 to $15 \mu \mathrm{l}$ ) of the PCR products were separated on $2 \%$ agarose gels in $1 \times$ TBE buffer $(90 \mathrm{mM}$ Trisborate and $2 \mathrm{mM}$ EDTA [pH 8.0]) at $80 \mathrm{~V}$ for $3 \mathrm{~h}$. Gels were stained with ethidium bromide and bands were visualized on a UV transilluminator. RAPD analysis was repeated at least three times for each primer. The presence or absence of bands that were consistently generated by RAPD analysis ( 1 for the presence and 0 for the absence of a particular sized band in the gel) was used to calculate the pairwise coefficients of similarity (Nei-Li distances). Cluster analysis with the neighbor joining method and bootstrap analysis were performed with the program FreeTree (18). The dendrogram was edited and visualized in TREEVIEW (26). Data from the RAPD analyses were used to calculate the ShanonWeaver's diversity index, using the formula $H=\sum[\mathrm{pi}-\ln (\mathrm{pi})]$, where pi is the proportion of each RAPD group (based on $100 \%$ similarity) in relation to the total number of RAPD groups per soil.

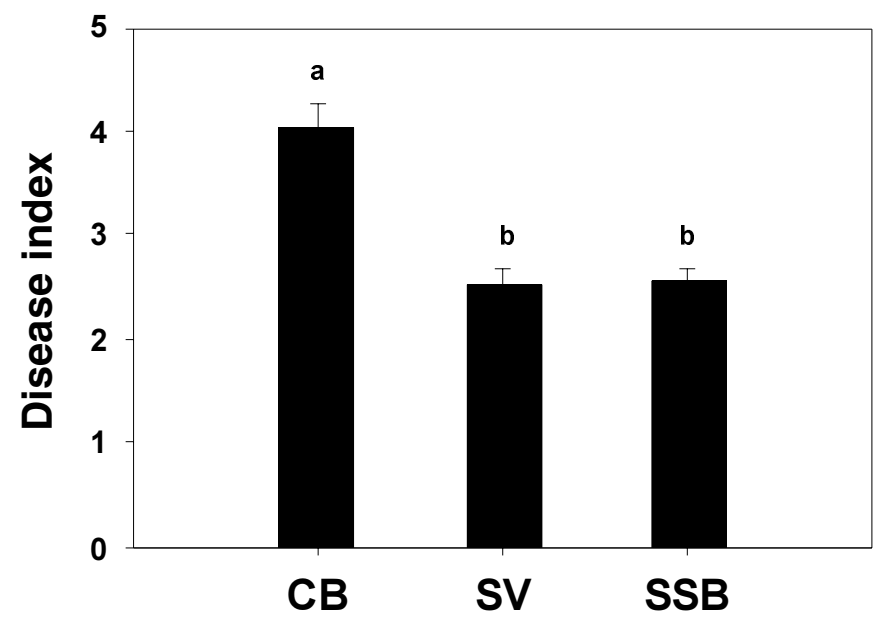

Fig. 1. Natural suppressiveness of soils CB, SV, and SSB to Gaeumannomyces graminis var. tritici. Soils were amended with $0.1 \%$ of an oat grain inoculum of $G$. graminis var. tritici. Plants were grown for 1 month under controlled conditions and disease caused by $G$. graminis var. tritici was scored on a 0 -to- 8 scale, where 0 indicates no disease and 8 indicates dead plant. Means of five replicates are shown. Means with the same letter are not statistically different according to Tukey's studentized range test $(P=0.05)$. Error bars represent the standard error of the mean. The experiment was repeated four times and representative results are shown.
Plate inhibition assays. PhlD+ Pseudomonas isolates obtained from roots of wheat grown in Dutch agricultural soils were inoculated at the edges of 9 -cm plates containing 1/5-strength PDA (initial $\mathrm{pH}=6.5$ ) and incubated for 2 days at $25^{\circ} \mathrm{C}$. Mycelial plugs (5-mm-diameter) of G. graminis var. tritici, $R$. solani, and Pythium ultimum var. sporangiiferum were transferred to the center of the plate. Plates were incubated at $25^{\circ} \mathrm{C}$ and the radial growth of the fungus toward the bacterial isolate was measured after 3 to 5 days and compared with the control (fungus only). For each isolate, growth inhibition of both G. graminis var. tritici and $R$. solani was determined in duplicate. Data from plate inhibition assays were used to construct similarity matrices, where a hierarchial cluster analysis was performed by the single linkage method (12).

Tn5-mutagenesis. 2,4-DAPG-deficient mutants of spontaneous rifampicin-resistant derivatives of Pseudomonas fluorescens strains SSB17 and Q8r1-96 were obtained by biparental mating with $E$. coli strain $\mathrm{S} 17 \lambda$ pir harboring the mini-Tn5lacZ element in plasmid pUT, according to protocols described by Sambrook and Russel (31). Transformants were selected on KMB supplemented with rifampicin and kanamycin and subsequently transferred to 98-well microtiter plates containing KMB broth. Transformants unable to produce a red pigment, which is not 2,4DAPG, but is characteristic for 2,4-DAPG-producing Pseudomonas strains (3), were selected after 1 week of growth at $25^{\circ} \mathrm{C}$. High-performance liquid chromatography (HPLC) was used to confirm the inability of these transformants to produce 2,4-DAPG (5). Plate inhibition assays with $G$. graminis var. tritici, $R$. solani, and Pythium ultimum var. sporangiiferum were used to further confirm the inability of mutant strains to inhibit these pathogens in vitro. RAPD analysis with primers M13, M12, and D7 was performed to confirm strain integrity. Southern blot analysis was used to determine the number of copies of the Tn5lacZ element in the 2,4-DAPG-deficient mutants.

Southern analysis and colony hybridizations. For Southern blot analysis, genomic DNA of wild type and mutant strains was extracted with the DNA Wizard Kit (Promega, Leiden, The Netherlands). Samples containing $2.0 \mu \mathrm{g}$ of DNA were digested with 5 units of KpnI and EcoRI (Promega), two enzymes for which restriction sites are not present in the kanamycin gene of the mini-Tn5lacZ element (14). Restrictions were performed in a total volume of $100 \mu \mathrm{l}$ at $37^{\circ} \mathrm{C}$ for $12 \mathrm{~h}$. Digested DNA was precipitated with $4 \mathrm{M} \mathrm{LiCl}$, washed with $70 \%$ ethanol, dissolved in $15 \mu \mathrm{l}$ of sterile distilled water, and separated on $1 \%$ agarose gels in $1 \times$ TBE. DNA and colony transfer to Hybond $\mathrm{N}^{+}$nylon membranes (Amersham Pharmacia Biotech, Roosendaal, Netherlands) were performed according to standard methods (31). Membrane washes and hybridizations were performed following standard procedures (31). High-stringent conditions comprised prehybridization for $1.5 \mathrm{~h}$ at $65^{\circ} \mathrm{C}$, hybridization for $12 \mathrm{~h}$ at $65^{\circ} \mathrm{C}$, membrane washing twice for $5 \mathrm{~min}$ each with $2 \times \mathrm{SSC}(1 \times \mathrm{SSC}$ is $0.15 \mathrm{M} \mathrm{NaCl}$ plus $0.015 \mathrm{M}$ sodium citrate)- $0.1 \%$ sodium dodecyl sulfate (SDS) at room temperature, and membrane washing twice each for $30 \mathrm{~min}$ with $0.1 \times \mathrm{SSC}-0.1 \% \mathrm{SDS}$ at $65^{\circ} \mathrm{C}$. A $575-\mathrm{bp}$ probe, specific for the kanamycin gene contained within the Tn5LacZ element, was obtained by direct PCR digoxigenin (DIG) labeling (Roche Corp., Basel, Switzerland) of the fragment using primers KM1 (5'-CCCGATGCGCCAGAGTTGTT) and KM2 (5'TCACCGAGGCAGTTCCATAGG).

Treatment of seeds with Pseudomonas. For bioassays and rhizosphere competence studies, wheat seeds (cv. Bussard) were coated with SSB17, Q8r1-96, or their 2,4-DAPG-deficient mutants in $1 \%$ methylcellulose to final densities of approximately $10^{3}, 10^{4}$, and $10^{6} \mathrm{CFU}$ per seed; seeds treated with $1 \%$ methylcellulose served as a control. Population densities of introduced Pseudomonas spp. strains SSB17, Q8r1-96, and their 2,4-DAPGdeficient mutants were assessed on uninfected wheat roots and on roots infected by G. graminis var. tritici. 
Statistical analysis. Prior to analysis of variance (ANOVA), data from population counts were $\log _{10}$-transformed and disease index data were ranked. Root dry weight data were analyzed directly by ANOVA followed by Tukey's studentized range test, after certifying normal distribution and homogeneity of variances (SAS Institute, Cary, NC). Data from bacterial population counts on $G$. graminis var. tritici- and $R$. solani-lesioned roots that did not present normal distribution after transformations $\log _{10}(\mathrm{CFU})$ were analyzed by the one-way nonparametric Kruskal-Wallis test and comparison of means of two treatments was performed by Wilcoxon's two sample test. Data from population increases were also analyzed by the one-way nonparametric Kruskal-Wallis test followed by Wilcoxon's two sample test. Data from rhizosphere competence assays were analyzed by nonlinear regression analysis to determine the relationship between the initial density of strains SSB17 and Q8r1-96 on seeds and their final density on roots of 1month-old wheat plants. The equation used was $Y=a \times X /(b+X)$, where $Y$ represents the final density (log CFU $\mathrm{g}^{-1}$ root), $X$ represents the initial density (log CFU per seed), $a$ represents the maximum final density, and $b$ represents the initial density necessary to reach half of the maximal final density (29). All experiments were performed at least twice and representative results are shown.

\section{RESULTS}

Natural suppressiveness of soils to G. graminis var. tritici. Characteristics of soils CB, SV, and SSB are shown in Table 1. Physical and chemical properties of these soils differ from TAD soils from Washington State (30). Major differences are that the Dutch soils have lower levels of nitrate, phosphorus, potassium, and silt content, and higher levels of organic matter and clay content compared with the four soils from Washington State. The three Dutch soils were tested in bioassays for suppressiveness to G. graminis var. tritici. When these soils were inoculated with $G$. graminis var. tritici, the disease index was significantly lower on roots of plants grown in SV and SSB soils compared with plants grown in $\mathrm{CB}$ soil (Fig. 1). No take-all symptoms were found on roots of wheat grown in soils not inoculated with $G$. graminis var. tritici (data not shown). Very similar levels of takeall suppressiveness were described for the Washington State soils (28). Based on these results and the occurrence of long-term wheat monoculture in the SV and SSB soils, they were classified as TAD soils, whereas CB soil was regarded as a G. graminis var. tritici-conducive soil. When inoculated with $R$. solani AG-8, root dry weights were significantly reduced in all three soils by approximately $40 \%$ compared with the healthy controls. No significant differences in reduction of root biomass were observed between the two Dutch TAD soils and the take-all conducive CB soil.

Frequency and diversity of 2,4-DAPG-producing Pseudomonas spp. in Dutch TAD soils. In CB soil, wheat rhizosphere population densities of phlD+ Pseudomonas spp. were relatively low and ranged from less than $10^{4}$ to $2.7 \times 10^{4} \mathrm{CFU} / \mathrm{g}$ of root (Table 2). In the SV and SSB soils, populations of phlD+ fluorescent Pseudomonas spp. ranged from $5.1 \times 10^{4}$ to $1.4 \times$ $10^{6} \mathrm{CFU} / \mathrm{g}$ of root (Table 2). These populations represented approximately 5 to $14 \%$ of the total population of fluorescent pseudomonads isolated from wheat roots and were, on average, 5- to 52-fold higher than populations of phlD+ fluorescent Pseudomonas spp. found on roots of wheat grown in the CB soil. These results demonstrate a correlation between relatively high populations of phlD+ fluorescent Pseudomonas spp. and suppressiveness to take-all of wheat.

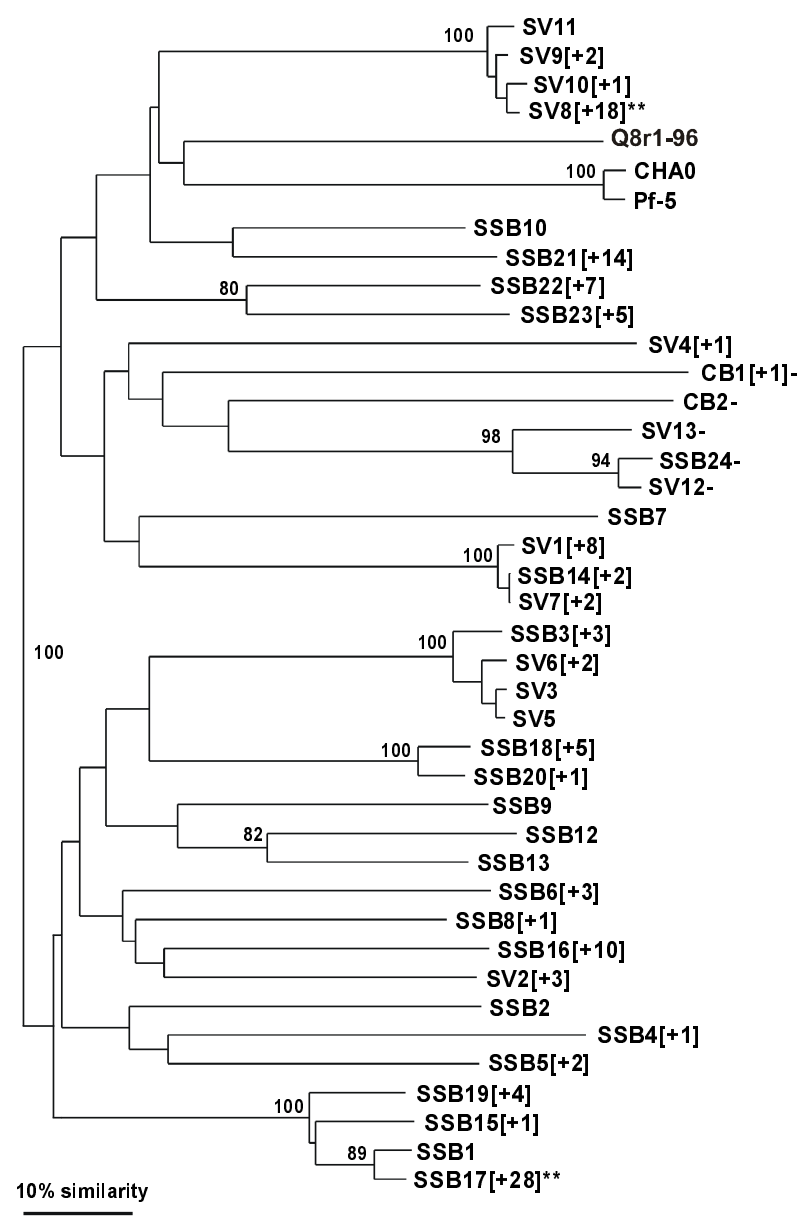

Fig. 2. Dendrogram of phlD+ fluorescent Pseudomonas spp. strains based on random amplified polymorphic DNA (RAPD) markers. The pairwise coefficients of similarity ( $\mathrm{Nei} / \mathrm{Li}$ distances) were clustered using the neighborjoining method. On roots of wheat grown in soil, SV, 11 (SV1 to SV11) different genotypic groups of $p h l D+$ isolates were found on the basis of $100 \%$ similarity. In soil SSB, 23 (SSB1 to SSB23) different groups were found. Each branch represents a unique genotypic group. Isolates followed by - are phlD- fluorescent Pseudomonas spp. Numbers between brackets represent the additional number of isolates in the RAPD group. Asterisks indicate the major genotypic groups in SV and SSB soils. Bootstrap values were calculated for 1,000 resampled data sets and only values equal or higher than $80 \%$ are shown.

TABLE 2. Frequency of phlD+ fluorescent Pseudomonas spp. in the wheat rhizosphere

\begin{tabular}{|c|c|c|c|c|c|c|}
\hline \multirow[b]{2}{*}{ Soil } & \multicolumn{3}{|c|}{ First experiment } & \multicolumn{3}{|c|}{ Second experiment } \\
\hline & $\begin{array}{c}\text { Total fluorescent } \\
\text { Pseudomonas spp. }{ }^{\mathrm{x}}\end{array}$ & $\begin{array}{l}\text { phlD+ fluorescent } \\
\text { Pseudomonas spp. }{ }^{\mathrm{y}}\end{array}$ & $\begin{array}{l}\text { \% phlD+ fluorescent } \\
\text { Pseudomonas spp. }\end{array}$ & $\begin{array}{c}\text { Total fluorescent } \\
\text { Pseudomonas spp. }{ }^{\mathrm{x}}\end{array}$ & $\begin{array}{l}\text { phlD+ fluorescent } \\
\text { Pseudomonas spp. }\end{array}$ & $\begin{array}{l}\text { \% phlD+ fluorescent } \\
\text { Pseudomonas spp. }\end{array}$ \\
\hline $\mathrm{CB}$ & $2.7 \times 10^{5}$ & $<10^{4}$ & $<0.1$ & $1.2 \times 10^{6}$ & $2.7 \times 10^{4}$ & 2.3 \\
\hline SV & $5.7 \times 10^{5}$ & $5.1 \times 10^{4}$ & 9.0 & $4.5 \times 10^{6}$ & $2.1 \times 10^{5}$ & 4.8 \\
\hline SSB & $1.1 \times 10^{6}$ & $1.1 \times 10^{5}$ & 14.0 & $1.1 \times 10^{7}$ & $1.0 \times 10^{6}$ & 12.7 \\
\hline
\end{tabular}

x Total population of fluorescent Pseudomonas spp. (CFU/g of root). Mean values of five replicates are given.

y Population of fluorescent Pseudomonas spp. harboring the phlD gene (CFU/g of root). Mean values of five replicates are given.

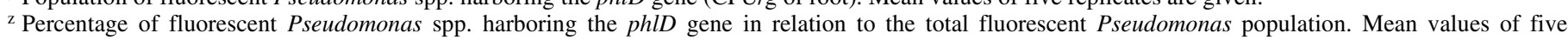
replicates are given. 
Analysis of the genotypic diversity of the isolated phlD+ fluorescent Pseudomonas spp. by RAPD analysis with primers M13, M12, and D7 generated a total of 58, 56, and 48 consistent RAPD markers, respectively, ranging in size from 190 to

TABLE 3. Clustering of phlD+ fluorescent Pseudomonas spp. by random amplified polymorphic DNA (RAPD) analysis ${ }^{\mathrm{t}}$

\begin{tabular}{|c|c|c|c|c|}
\hline $\begin{array}{l}\text { Origin/type } \\
\text { of isolate }\end{array}$ & $\begin{array}{l}\text { No. of } \\
\text { isolates }\end{array}$ & $\begin{array}{l}\text { RAPD } \\
\text { groups }^{u}\end{array}$ & $\begin{array}{c}\text { Major } \\
\text { groups }(\%)^{\mathrm{v}}\end{array}$ & $\begin{array}{c}\text { Shanon- } \\
\text { Weaver index }\end{array}$ \\
\hline SV soil & 48 & 11 & 39.6 (SV8) & 32.2 \\
\hline SSB soil & 113 & 23 & 25.7 (SSB17) & 84.2 \\
\hline SV and SSB soils ${ }^{x}$ & 6 & 1 & $\ldots$ & $\ldots$ \\
\hline $\begin{array}{l}\text { Non-2,4-DAPG } \\
\text { producers }^{\mathrm{y}}\end{array}$ & 6 & 5 & $\ldots$ & $\cdots$ \\
\hline Reference strains $\mathrm{s}^{\mathrm{z}}$ & 3 & 3 & $\ldots$ & $\ldots$ \\
\hline
\end{tabular}

${ }^{\mathrm{t}}$ phlD+ isolates were obtained from roots of wheat grown in SV and SSB soils.

"RAPD groups were defined with primers D7, M12, and M13 on the basis of $100 \%$ similarity.

${ }^{v}$ Major group refers to the percentage of the total number of phlD+ fluorescent Pseudomonas represented by a single dominant genotype.

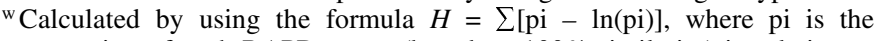
proportion of each RAPD group (based on $100 \%$ similarity) in relation to the total number of RAPD groups per soil.

${ }^{x}$ Present in both, SV and SSB soils.

y phlD-isolates include CB1, CB2, CB3, SV12, SV13, and SSB24 and were obtained from roots of wheat grown in $\mathrm{CB}, \mathrm{SV}$, and SSB soils.

${ }^{\mathrm{z}}$ Reference strains include Pseudomonas fluorescens strains CHA0, Pf5, and Q8r1-96.
2,070 bp. Reproducibility of the RAPD amplifications was confirmed in three independent experiments and the reliability of the dendrogram topology (Fig. 2) was evaluated by bootstrap analysis using 1,000 resampled data sets. Among a total of 161 isolates of phlD+ fluorescent Pseudomonas spp. obtained from roots of wheat grown in SV and SSB soil, 33 unique groups were identified and only one RAPD group, represented by isolates SSB14 and SV7, was found in both soils (Fig. 2; Table 3). The major genotypic groups found on roots of wheat grown in SV and SSB soils represented on average 40 and $26 \%$, respectively, of the total number of phlD+ fluorescent Pseudomonas spp. isolates from SV and SSB soils (Table 3). The major genotypic group (SV8) found in SV soil clustered very distantly from the major genotypic group (SSB17) found in SSB soil (Fig. 2). Isolates from SV and SSB soils clustered distantly from 2,4-DAPG-producing reference strains CHA0, Pf5, and Q8r1-96 and from 2,4-DAPG-nonproducing isolates (groups CB1, CB2, SV12, SV13, and SSB24) obtained from CB, SV, and SSB soils (Fig. 2). The ShanonWeaver's diversity index was higher for populations of phlD+ fluorescent Pseudomonas spp. isolated from SSB soil than for those from SV soil (Table 3), indicating a higher level of genotypic diversity in SSB soil.

In addition to genotypic clustering by RAPD analysis, data from plate inhibition assays were used to phenotypically group the isolates on the basis of their capacity to inhibit G. graminis var. tritici and $R$. solani. Based on $G$. graminis var. tritici mycelial inhibition, a total of seven clusters were obtained. Five of these

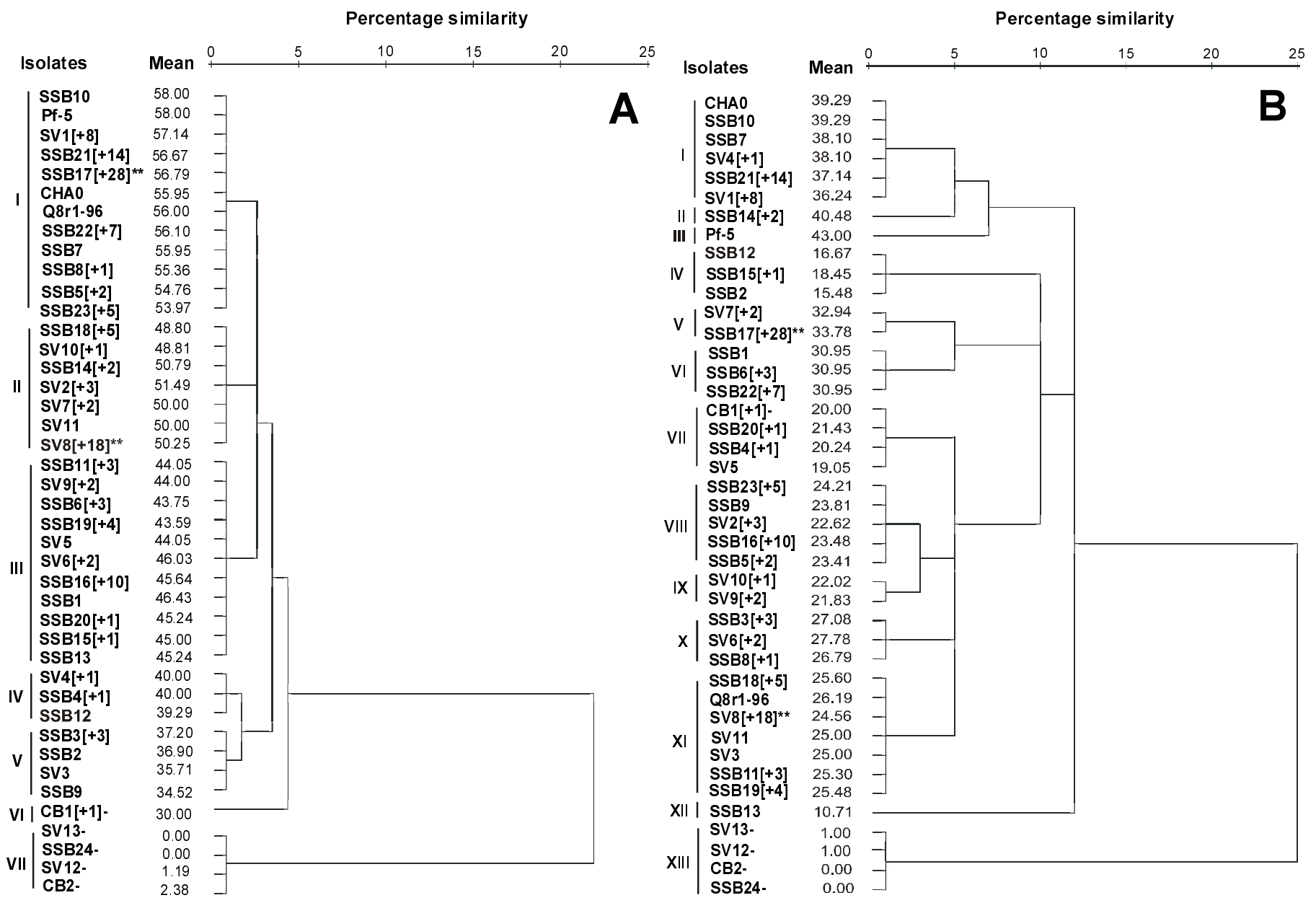

Fig. 3. Cluster analysis of in vitro inhibition of A, Gaeumannomyces graminis var. tritici and $\mathbf{B}$, Rhizoctonia solani by phlD+ fluorescent Pseudomonas spp. Hierarchial, single linkage cluster analysis was computed using the mean inhibition of mycelial growth on plates given by a certain Pseudomonas isolate when compared with the control (the fungus only). Numbers between brackets represent the number of additional isolates in the cluster. Asterisks indicate the major genotypic groups in SV and SSB soils. Isolates followed by - are phlD- fluorescent Pseudomonas spp. Mean refers to the mean percentage inhibition relative to the control. 
clusters (I to V) contained isolated 2,4-DAPG producers and reference strains Pf5, CHA0, and Q8r1-96, and two clusters (VI and VII) contained phlD- isolates that did not produce 2,4-DAPG. Thirteen clusters were obtained based on inhibition of mycelial growth of $R$. solani. Clusters I to XI contained isolated 2,4-DAPG producers and reference strains and clusters XII and XIII contained non-2,4-DAPG producers (Fig. 3). Comparison of the cluster analyses indicates that 2,4-DAPG-producing isolates are more inhibitory in vitro to $G$. graminis var. tritici than to $R$. solani (Fig. 3). The mean inhibition of mycelial growth by phlD+ fluorescent Pseudomonas spp. isolates and 2,4-DAPG-producing reference strains ranged from approximately 35 to $58 \%$ for $G$. graminis var. tritici and from approximately 11 to $43 \%$ for $R$. solani. For 2,4-DAPG nonproducing isolates, inhibition of $G$. graminis var. tritici ranged from 0 to $30 \%$ and inhibition of $R$. solani ranged from 0 to $20 \%$. Most phenotypic groups contained more than one RAPD group and isolates belonging to the same RAPD group (based on $100 \%$ similarity) were always grouped in the same phenotypic group (Figs. 2 and 3). Strain SSB17, which is a representative of the major RAPD group found on roots of wheat grown in SSB soil (Fig. 2; Table 3), clustered in the phenotypic group that was most inhibitory to G. graminis var. tritici (Fig. 3) and was selected for further studies. Strain Q8r1-96, which represents the major RAPD group among 2,4-DAPGproducing Pseudomonas spp. isolated from wheat grown in the Quincy TAD soil from Washington State (29), was included for comparison purposes. Q8r1-96 clustered in the same G. graminis var. tritici-phenotypic group as SSB17 (Fig. 3), but is genotypically different (Fig. 2).

Role of 2,4-DAPG-producing Pseudomonas spp. in Dutch TAD soils. If 2,4-DAPG-producing fluorescent Pseudomonas spp. play a determinative role in the natural suppressiveness of Dutch TAD soils, then introduction of a 2,4-DAPG-producing strain into the conducive soil should give suppressiveness to G. graminis var. tritici to a level similar to that obtained in the complementary TAD soil. Furthermore, if 2,4-DAPG is a key metabolite in suppression of G. graminis var. tritici, then 2,4-DAPG-deficient mutants should have a reduced ability to suppress take-all of wheat. Tn5 mutagenesis of Pseudomonas fluorescens strains SSB17 and Q8r1-96 generated 1,078 and 686 transformants, respectively. For strains SSB17 and Q8r1-96, 4 and 2 transformants, respectively, did not produce the red pigment characteristic of 2,4DAPG producers. RAPD analysis confirmed strain integrity of all six mutants, and HPLC analysis showed that all six mutants were defective in 2,4-DAPG production. In plate inhibition assays, wild-type strains SSB17 and Q8r1-96 caused clear inhibition of mycelial growth of G. graminis var. tritici, R. solani, and Pythium ultimum var. sporangiiferum, whereas the mutants caused no inhibition of these pathogens (data not shown). Southern blot analysis revealed that all mutants had a single transposon insertion. Mutants 9H4, derived from SSB17, and 4C5, derived from Q8r196 , were selected for the bioassays.

Strain SSB17 and its 2,4-DAPG-deficient mutant 9H4 were introduced via seed treatment into the take-all conducive $\mathrm{CB}$ soil amended with $G$. graminis var. tritici inoculum at initial densities of approximately $10^{3} \mathrm{CFU}$ per seed. SSB17 and 9H4 established rhizosphere population densities of $5.0 \times 10^{6}$ and $9.0 \times 10^{6} \mathrm{CFU} / \mathrm{g}$ of root, respectively, after 4 weeks of plant growth. Population densities of the wild type and mutant were not significantly different and were similar to the density of indigenous 2,4-DAPG producers $\left(5.0 \times 10^{6} \mathrm{CFU} / \mathrm{g}\right.$ of root) found on roots of wheat grown in the SSB soil amended with $G$. graminis var. tritici inoculum. Treatment of seeds with strain SSB17 significantly reduced take-all severity and provided control to the same level as found in the SSB TAD soil (Fig. 4A). Mutant 9H4 did not reduce disease severity caused by G. graminis var. tritici (Fig. 4A). These results provide further evidence that phlD+ fluorescent Pseudomonas spp. are a key component of the suppressiveness that operates in the SSB TAD soil and that 2,4-DAPG is the major determinant of take-all suppression by strain SSB17. In independent experiments, similar results were found for strain Q8r1-96 and its 2,4-DAPG-deficient mutant 4C5 (Fig. 4B). Although there were no differences between strains SSB17 and Q8r1-96 in their ability to suppress take-all, there was a significant difference in their rhizosphere competence (Fig. 5). In spite of the fact that strain Q8r1-96 was isolated from a different wheat cultivar grown in a physicochemically different soil from another geographical region, it was more rhizosphere competent than strain SSB17.
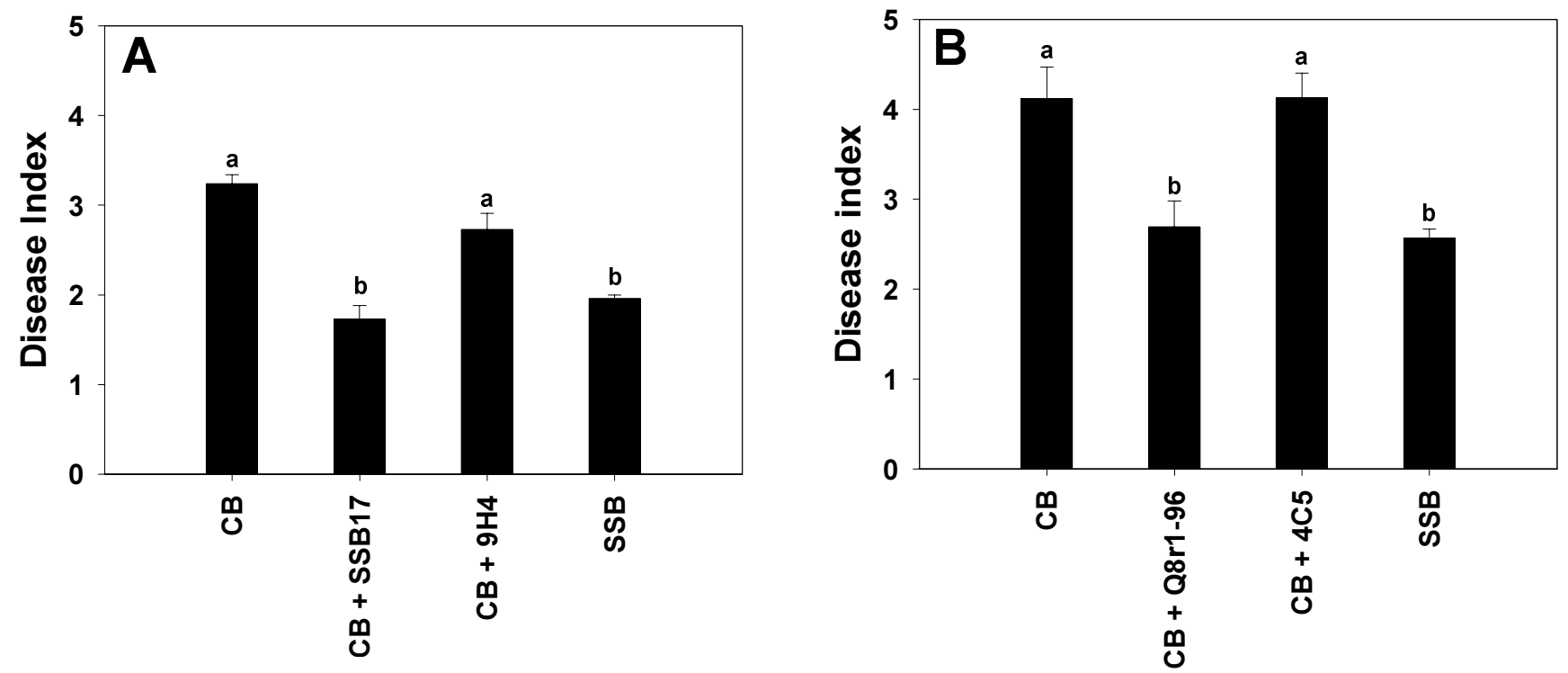

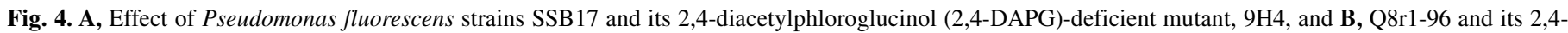

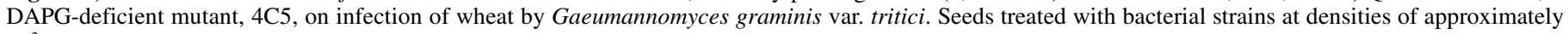

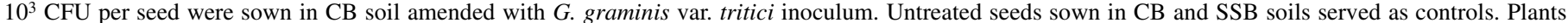

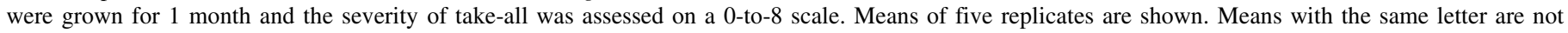

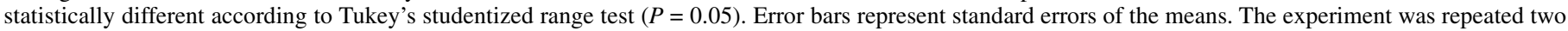
times and representative results are shown. 
Dose-response studies showed that strain Q8r1-96 required lower initial densities on seeds than strain SSB17 to reach the same final population on roots (Fig. 5). When comparing dose-response kinetics of the wild-type strains SSB17 and Q8r1-96 with those obtained for their respective 2,4-DAPG-deficient mutants, 9H4 and 4C5, no differences were found (Fig. 5). These results suggest that 2,4-DAPG production does not contribute to the rhizosphere competence of strains SSB17 and Q8r1-96.

Effect of take-all and Rhizoctonia root rot on rhizosphere population densities of 2,4-DAPG-producing fluorescent Pseudomonas spp. The influence of $G$. graminis var. tritici and $R$. solani infections on wheat root colonization by indigenous and introduced phlD+ fluorescent Pseudomonas spp. was studied. Population densities of indigenous pseudomonads and phlD+ fluorescent Pseudomonas spp. were assessed on healthy and $G$. graminis var. tritici- or $R$. solani-infected roots of wheat grown in SV and SSB soils, and in more detail on nonlesioned and lesioned root sections of G. graminis var. tritici- or $R$. solani-infected roots (Tables 4 and 5). When roots of wheat grown in SV and SSB soils were infected with $G$. graminis var. tritici, or $R$. solani, densities of phlD+ fluorescent Pseudomonas spp. on the whole root systems increased significantly by five to eightfold. Identical increases were observed for the total fluorescent Pseudomonas population on $G$. graminis var. tritici-infected roots and on roots infected with $R$. solani. When population densities of both total and phlD+ fluorescent Pseudomonas spp. were compared in more detail on lesioned and nonlesioned root sections of infected roots, G. graminis var. tritici infection led to increases ranging from 4to 15 -fold. Similar increases in population densities of total and phlD+ fluorescent Pseudomonas spp. were observed in the SV and SSB soils. Population densities of phlD+ fluorescent Pseudomonas spp. were up to sixfold greater on $R$. solani-lesioned root sections than on nonlesioned root sections. These increases were not significantly different from the increases observed on $G$. graminis var. tritici-lesioned root sections for both SV and SSB soils $(P=0.26$ and 0.47 , respectively).

The effect of $G$. graminis var. tritici on root colonization was also determined for Pseudomonas fluorescens strains SSB17, Q8r1-96, and their respective 2,4-DAPG-defective mutants, 9H4 and 4C5, all of which were introduced at two different initial densities (Table 6). After 3 weeks of plant growth, rhizosphere population densities of the wild-type strains and their respective mutants were not significantly different from each other in presence or in absence of $G$. graminis var. tritici. Population densities of SSB17 and 9H4 were significantly lower than population densities of Q8r1-96 and 4C5, irrespective of the presence of $G$. graminis var. tritici. For both initial densities of the introduced strains, infections of wheat roots by G. graminis var. tritici did not lead to significant increases in their population densities.

\section{DISCUSSION}

The results of this study indicate that 2,4-DAPG-producing Pseudomonas spp. play a key role in the suppressiveness of two Dutch TAD soils. First, 2,4-DAPG-producing Pseudomonas spp. were present on roots of wheat grown in both TAD soils at densities up to approximately $10^{6} \mathrm{CFU} / \mathrm{g}$ of root, densities that are equal or higher than the threshold density $\left(10^{5} \mathrm{CFU} / \mathrm{g}\right.$ of root) of 2,4-DAPG-producing fluorescent Pseudomonas strains required to control take-all (28). In the complementary take-all conducive soil, population densities of 2,4-DAPG-producing fluorescent Pseudomonas spp. were below this threshold density. Second, introduction of 2,4-DAPG-producing strain SSB17, representative of the dominant genotypic group found in one of the Dutch TAD soils, into the take-all conducive soil at rhizosphere population densities similar to the densities of indigenous 2,4-DAPGproducing fluorescent Pseudomonas spp. found in TAD soils, provided control of take-all to the same level as found in the complementary TAD soil. Third, a mutant of SSB17 deficient in 2,4-DAPG production was not able to control take-all of wheat, suggesting that 2,4-DAPG is a key determinant in take-all suppression. Previously, the role of 2,4-DAPG-producing fluorescent Pseudomonas spp. in TAD soils had been demonstrated only in Washington State. Gerlagh (17) postulated from his elegant and classic studies of TAD in Dutch polders that specific suppression possibly involves antibiotic production by soil microorganisms. This report identifies for the first time, at least in part, the mechanism and microorganisms that contribute to the suppressiveness of Dutch TAD soils.

The densities of indigenous 2,4-DAPG-producing Pseudomonas spp. found on roots of wheat grown in the Dutch TAD soils were quantitatively similar to the densities found in four TAD soils
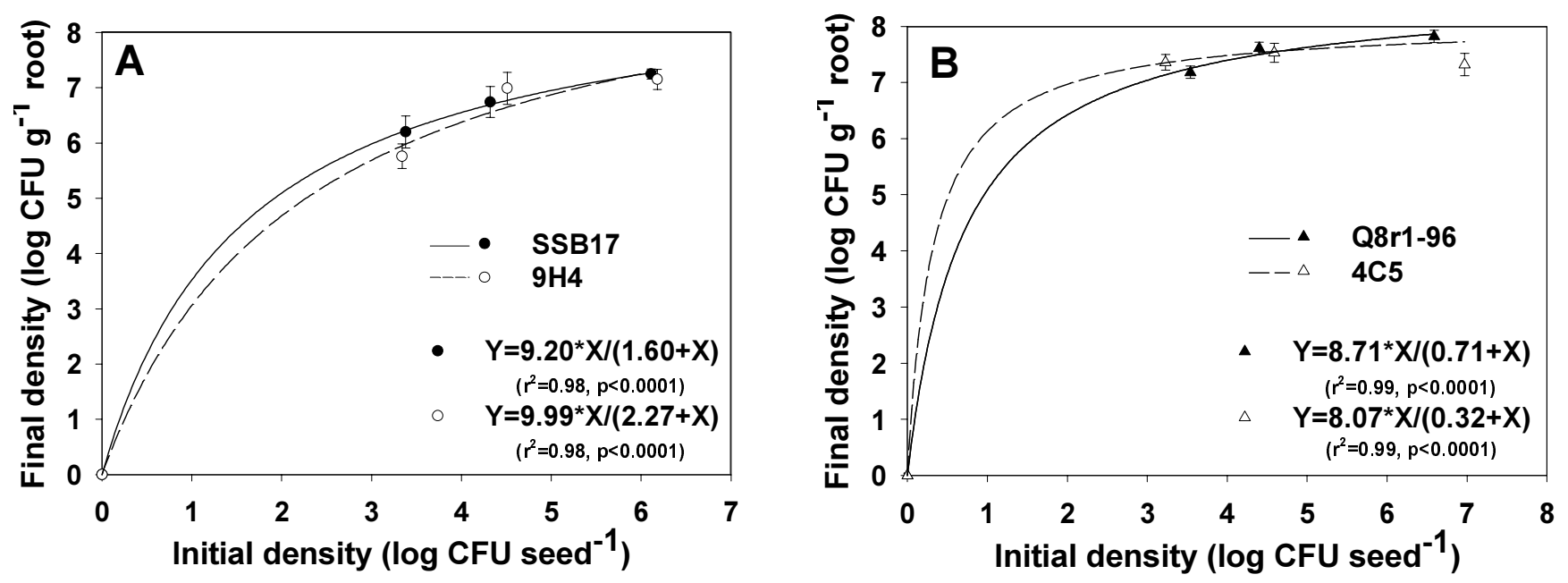

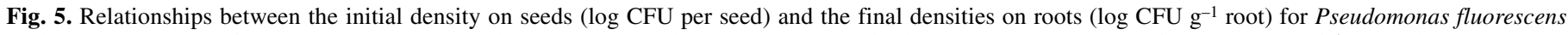

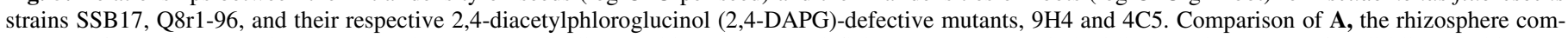

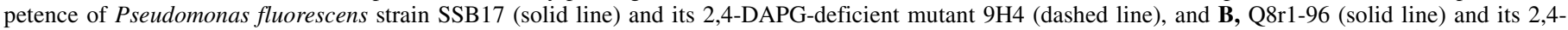

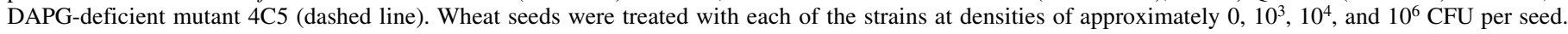

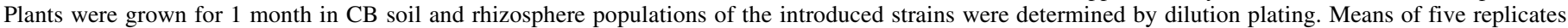

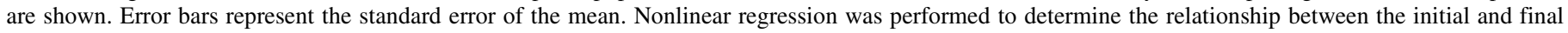

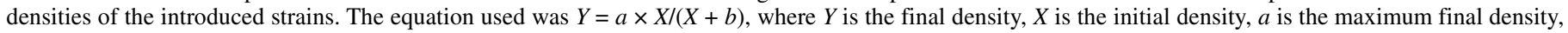
and $b$ is the initial density necessary to reach half of the maximum final density. The experiment was repeated twice and representative results are shown. 
from Washington State $(28,30)$. However, the genotypes of 2,4DAPG-producers responsible for TAD in the Dutch soils differed from those in Washington State TAD soils $(24,29)$. For example, Raaijmakers and Weller (29) identified 16 RAPD groups among 101 phlD+ isolates obtained from roots of wheat grown in Quincy, Washington TAD soil, and one group comprised 50\% of the isolates. This genotype also was dominant on roots of wheat grown in Moses Lake and Lind, Washington TAD soils and belonged to BOX-PCR group D as defined by McSpaddenGardener et al. (24). In the current study, 33 distinct RAPD groups were identified among 161 phlD+ isolates from the two Dutch TAD soils, but the SV and SSB soils had different dominant groups that represented 40 and 26\%, respectively, of the isolates. All of the Dutch isolates clustered distantly from Q8r1-96, a representative of the dominant phlD+ isolates from the three Washington TAD soils. Furthermore, the dominant Dutch isolates corresponded to BOX-PCR groups $\mathrm{M}$ and $\mathrm{F}$, which do not occur in Washington TAD soils.
The Shanon-Weaver's index indicated that the diversity among 2,4-DAPG producers was higher in the SSB soil than in the SV soil. This was unexpected because we had hypothesized that the longer history of wheat monoculture in the SSB soil compared with the SV soil would have enriched for a narrower range of genotypes. One explanation for the difference in diversity index between the two soils may be the fact that under field conditions different wheat cultivars were grown in these soils. Wheat cv. Bussard, used in the experiments described in this study, was also the cultivar grown in SSB soil in the field, whereas cv. Monopol was grown successively in the SV soil under field conditions. The influence of the host plant and cultivar on the composition of the microflora is well established for several systems. For example, certain wheat cultivars select for specific populations of Pseudomonas putida that are antagonistic to the causal agents of apple replant disease (23), and different tomato genotypes provide better support for the growth and biocontrol activity of Bacillus cereus (37). Furthermore, the significance of the plant cultivar has been

TABLE 4. Influence of Gaeumannomyces graminis var. tritici on wheat root colonization by indigenous fluorescent Pseudomonas spp.

\begin{tabular}{|c|c|c|c|c|c|c|c|c|c|c|c|c|}
\hline \multirow[b]{3}{*}{ Soil } & \multicolumn{6}{|c|}{ Healthy $\times$ diseased roots ${ }^{v}$} & \multicolumn{6}{|c|}{ Nonlesioned $\times$ lesioned root sections of diseased plants ${ }^{\mathrm{w}}$} \\
\hline & \multicolumn{2}{|c|}{ Total pseudomonads ${ }^{\mathrm{x}}$} & \multirow[b]{2}{*}{ Increase $^{\mathrm{z}}$} & \multicolumn{2}{|c|}{$p h l D+{ }^{\mathrm{y}}$} & \multirow[b]{2}{*}{ Increase $^{\mathrm{Z}}$} & \multicolumn{2}{|c|}{ Total pseudomonads ${ }^{\mathrm{x}}$} & \multirow[b]{2}{*}{ Increase $^{\mathrm{z}}$} & \multicolumn{2}{|c|}{ phlD+y } & \multirow[b]{2}{*}{ Increase $^{z}$} \\
\hline & $\begin{array}{c}\text {-G. graminis } \\
\text { var. tritici }\end{array}$ & $\begin{array}{c}+G . \text { graminis } \\
\text { var. tritici }\end{array}$ & & $\begin{array}{c}\text {-G. graminis } \\
\text { var. tritici }\end{array}$ & $\begin{array}{c}+G . \text { graminis } \\
\text { var. tritici }\end{array}$ & & $\begin{array}{l}\text {-G. graminis } \\
\text { var. tritici }\end{array}$ & $\begin{array}{c}+G . \text { graminis } \\
\quad \text { var. tritici }\end{array}$ & & $\begin{array}{c}\text {-G. graminis } \\
\text { var. tritici }\end{array}$ & $\begin{array}{c}+G . \text { graminis } \\
\quad \text { var. tritici }\end{array}$ & \\
\hline SV & $3.9 \times 10^{6}$ & $3.4 \times 10^{7 *}$ & 8.7 & $7.6 \times 10^{5}$ & $3.7 \times 10^{6 *}$ & 5.0 & $5.6 \times 10^{6}$ & $5.6 \times 10^{7}$ & 10.1 & $4.9 \times 10^{5}$ & $4.8 \times 10^{6}$ & 9.7 \\
\hline SSB & $8.1 \times 10^{6}$ & $4.9 \times 10^{7 *}$ & 6.1 & $7.3 \times 10^{5}$ & $4.3 \times 10^{6 *}$ & 6.0 & $8.8 \times 10^{6}$ & $3.8 \times 10^{7 *}$ & 4.3 & $2.7 \times 10^{5}$ & $4.0 \times 10^{6 *}$ & 14.8 \\
\hline
\end{tabular}

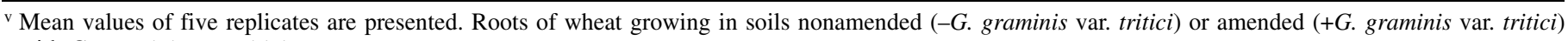
with $G$. graminis var. tritici.

${ }^{w}$ Nonlesioned and lesioned root sections of plants infected by G. graminis var. tritici.

x Populations of total fluorescent Pseudomonas spp. (CFU g ${ }^{-1}$ root).

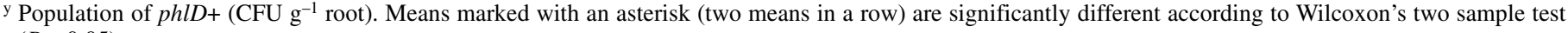
$(P=0.05)$.

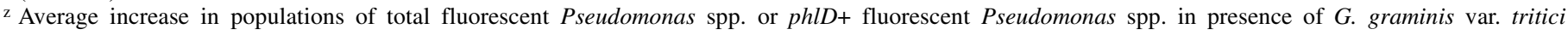
(+G. graminis var. tritici/-G. graminis var. tritici).

TABLE 5. Influence of Rhizoctonia solani on wheat root colonization by indigenous fluorescent Pseudomonas spp.

\begin{tabular}{|c|c|c|c|c|c|c|c|c|c|c|c|c|}
\hline \multirow[b]{3}{*}{ Soil } & \multicolumn{6}{|c|}{ Healthy $\times$ diseased roots ${ }^{v}$} & \multicolumn{6}{|c|}{ Non-lesioned $\times$ lesioned root sections of diseased plants ${ }^{\mathrm{w}}$} \\
\hline & \multicolumn{2}{|c|}{ Total pseudomonads ${ }^{\mathrm{x}}$} & \multirow[b]{2}{*}{ Increase $^{\mathrm{z}}$} & \multicolumn{2}{|c|}{$p h l D+{ }^{\mathrm{y}}$} & \multirow[b]{2}{*}{ Increase $^{\mathrm{z}}$} & \multicolumn{2}{|c|}{ Total pseudomonads ${ }^{\mathrm{x}}$} & \multirow[b]{2}{*}{ Increase $^{\mathrm{z}}$} & \multicolumn{2}{|c|}{$p h l D+\mathrm{y}$} & \multirow[b]{2}{*}{ Increase $^{\mathrm{z}}$} \\
\hline & - R. solani & $+R$. solani & & $-R$. solani & $+R$. solani & & $-R$. solani & $+R$. solani & & $-R$. solani & $+R$. solani & \\
\hline SV & $1.5 \times 10^{7}$ & $1.1 \times 10^{8 *}$ & 7.7 & $8.5 \times 10^{5}$ & $3.9 \times 10^{6 *}$ & 4.6 & $8.7 \times 10^{7}$ & $1.4 \times 10^{8}$ & 1.6 & $5.5 \times 10^{6}$ & $2.3 \times 10^{6}$ & 0.4 \\
\hline SSB & $1.7 \times 10^{7}$ & $1.0 \times 10^{8 *}$ & 6.3 & $1.7 \times 10^{6}$ & $1.1 \times 10^{7 *}$ & 6.6 & $5.3 \times 10^{7}$ & $1.6 \times 10^{8 *}$ & 3.1 & $3.0 \times 10^{6}$ & $1.9 \times 10^{7 *}$ & 6.2 \\
\hline
\end{tabular}

${ }^{\mathrm{v}}$ Mean values of five replicates are presented. Roots of wheat growing in soil nonamended (-R. solani) or amended (+R. solani) with $R$. solani.

${ }^{w}$ Nonlesioned and lesioned root sections of plants infected by $R$. solani.

x Populations of total fluorescent Pseudomonas spp. (CFU g ${ }^{-1}$ root).

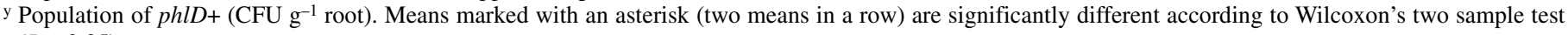
$(P=0.05)$.

${ }^{\mathrm{z}}$ Average increase in populations of total fluorescent Pseudomonas spp. or phlD+fluorescent Pseudomonas spp. in presence of $R$. solani (+R. solanil-R. solani).

TABLE 6. Influence of Gaeumannomyces graminis var. tritici on rhizosphere colonization of wheat by introduced Pseudomonas fluorescens strains

\begin{tabular}{|c|c|c|c|c|}
\hline \multirow[b]{2}{*}{ Isolate } & \multirow{2}{*}{$\begin{array}{l}\text { Initial density } \\
\text { (CFU per seed) }\end{array}$} & \multicolumn{2}{|c|}{ Final density $\left(\mathrm{CFU} \mathrm{g}^{-1} \text { root }\right)^{\mathrm{y}}$} & \multirow[b]{2}{*}{ Increase $^{\mathrm{z}}$} \\
\hline & & -G. graminis var. tritici & $+G$. graminis var. tritici & \\
\hline SSB 17 & $2.1 \times 10^{4}$ & $1.0 \times 10^{7} \mathrm{a}$ & $1.9 \times 10^{7} \mathrm{a}$ & 1.9 \\
\hline SSB17 & $1.3 \times 10^{6}$ & $1.9 \times 10^{7} \mathrm{a}$ & $3.1 \times 10^{7} \mathrm{a}$ & 1.6 \\
\hline $9 \mathrm{H} 4$ & $3.2 \times 10^{4}$ & $2.3 \times 10^{7} \mathrm{a}$ & $2.4 \times 10^{7} \mathrm{a}$ & 1.0 \\
\hline $9 \mathrm{H} 4$ & $1.5 \times 10^{6}$ & $1.9 \times 10^{7} \mathrm{a}$ & $2.6 \times 10^{7} \mathrm{a}$ & 1.4 \\
\hline Q8r1-96 & $2.5 \times 10^{4}$ & $4.7 \times 10^{7} \mathrm{~b}$ & $3.7 \times 10^{7} \mathrm{~b}$ & 0.8 \\
\hline Q8r1-96 & $3.9 \times 10^{6}$ & $7.4 \times 10^{7} \mathrm{~b}$ & $9.1 \times 10^{7} \mathrm{~b}$ & 1.2 \\
\hline $4 \mathrm{C} 5$ & $3.9 \times 10^{4}$ & $4.2 \times 10^{7} \mathrm{~b}$ & $5.7 \times 10^{7} \mathrm{~b}$ & 1.4 \\
\hline $4 \mathrm{C} 5$ & $9.3 \times 10^{6}$ & $7.4 \times 10^{7} \mathrm{~b}$ & $7.1 \times 10^{7} \mathrm{~b}$ & 1.0 \\
\hline
\end{tabular}

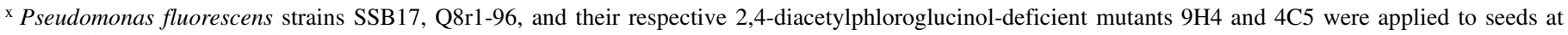
two different initial densities.

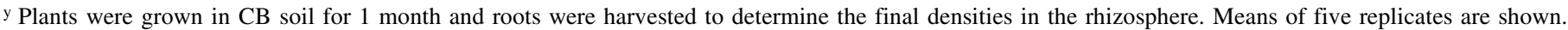
Means followed by the same letter within columns are not significantly different according to Wilcoxon's two sample test $(P=0.05)$.

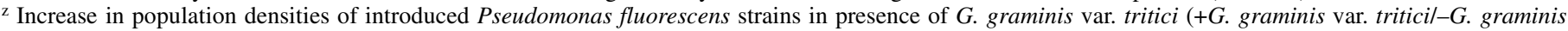
var. tritici). 
recently demonstrated at the physiological level. Significant changes in the expression of the phl biosynthetic operon of Pseudomonas fluorescens strain CHA0 were detected on different maize cultivars (25). Studies using different profiling techniques suggested a significant level of endemism for wheat-associated phlD+ fluorescent Pseudomonas spp. (40). Given the influence a cultivar may have on the composition and activity of phlD+ isolates, the differences between genotypes found in SV and SSB soils as well as between Dutch and U.S. TAD soils may be due to the different wheat cultivars used in different geographical regions and in different fields within a specific region. The effect of wheat cultivars on the genotypic diversity of 2,4-DAPG-producing Pseudomonas spp. will be addressed in future studies.

Comparison of the genotypic clustering of the isolates with the clustering based on in vitro inhibition of mycelial growth of $G$. graminis var. tritici and $R$. solani revealed that this latter approach was less discriminatory. In several host-pathogen systems, antibiotic production by antagonistic microorganisms in vitro does not correlate well with the level of suppression of diseases obtained in situ $(33,44)$. However, good correlation was found between in vitro inhibition and suppression of G. graminis var. tritici in situ by pseudomonads isolated from wheat roots grown in a TAD soil from Washington State (41). In this context, it is interesting to note that the dominant genotypic group found in the Dutch TAD soil, represented by strain SSB17, clustered closely together with Q8r1-96 in the phenotypic groups that were most inhibitory to the take-all fungus. In contrast, SSB17 and Q8r1-96 did not belong to the phenotypic group that was most inhibitory to $R$. solani. More isolates representative of the genotypic and phenotypic groups need to be tested in biocontrol assays to support the earlier results obtained by Weller et al. (41).

Strain SSB17 and strain Q8r1-96, when introduced into the conducive soil (CB) via seed treatment at low densities of approximately $10^{3} \mathrm{CFU}$ per seed were able to suppress $G$. graminis var. tritici to the same extent as occurred naturally in the suppressive soil (SSB). However, their 2,4-DAPG-deficient mutants $9 \mathrm{H} 4$ and $4 \mathrm{C} 5$, respectively, did not protect wheat plants against take-all. Although 2,4-DAPG plays a key role in take-all suppression, it does not contribute to the rhizosphere competence of 2,4-DAPG producers, because SSB17 and Q8r1-96 colonized wheat roots to the same extent as their respective 2,4-DAPG-deficient mutants. Similar results were obtained in experiments employing Pseudomonas fluorescens strain F113 and its 2,4-DAPG-defective mutant (7). In contrast to 2,4-DAPG, biosynthesis of phenazine antibiotics was shown to significantly contribute to the rhizosphere competence of Pseudomonas fluorescens 2-79 and Pseudomonas aureofaciens 30-84 (22). Recently, Raaijmakers and Weller (29) demonstrated that Q8r1-96 is much more aggressive as a colonist of wheat roots than other genotypes and it is now known that this unique colonizing ability is shared by strains from other soils that are genotypically similar to strain Q8r1-96. Strain Q8r1-96 was more rhizosphere competent than SSB17 (Fig. 5; Table 6), even though the studies were conducted in raw Dutch soil. This finding supports the suggestion that the rhizosphere competence of Q8r196 is minimally affected by the physicochemical characteristics of the soil (29) in which it is growing.

One of the key questions about the phenomenon of TAD is the basis of the enrichment of the antagonist responsible for specific suppression and the effect of the soil environment on the development and expression of suppressiveness. We found no quantitative differences in the population densities of 2,4-DAPG-producing fluorescent pseudomonads on roots of wheat grown in Dutch TAD soils compared with densities reported on roots of wheat grown in Washington State TAD soils $(28,30)$. These findings suggest that the enrichment is independent of the physical and chemical characteristics of the soil. Classical studies of TAD demonstrated that TAD is a field phenomenon requiring the take-all pathogen, a susceptible host, and at least one outbreak of severe disease. Some early studies suggested that the take-all pathogen, rather than the host plant, is primarily responsible for the selection of specific antagonists (4,6,17,32,36,42,45). For example, Gerlagh (17) and Zogg and Jaggi (45) induced suppressiveness to take-all by repeatedly adding mycelium of $G$. graminis var. tritici to soil, but the relationship of this type of suppression to TAD is still not known. In an attempt to begin to address the question about the basis of enrichment of 2,4-DAPG producers in Dutch TAD soils, we compared populations of fluorescent pseudomonads on healthy and diseased roots and on segments of roots from diseased plants with and without lesions. As has been demonstrated many times in the literature $(6,39)$, we found that roots with take-all lesions supported significantly larger populations of fluorescent pseudomonads than healthy roots. Also, 2,4-DAPG producers were enriched on diseased roots but not to a greater extent than the total population of fluorescent Pseudomonas spp. Furthermore, no significant increases in population densities of introduced strains SSB17 and Q8r1-96 were observed upon infection of wheat roots by $G$. graminis var. tritici. Based upon these limited studies at this time, we conclude that increased nutrient availability upon fungal infection is primarily responsible for the enrichment of 2,4-DAPG producers.

In light of the results of this and earlier studies $(28,30)$, the specificity of the suppression that operates in TAD soils becomes interesting especially when considering the broad-spectrum activity of 2,4-DAPG against many fungal pathogens (20). Australian TAD soils were shown also to have certain levels of suppressiveness to $R$. solani, Gibberella zeae, Pythium irregulare, Cochliobolus sativus, and Fusarium culmorum (43). The results of our study, however, indicated that the two Dutch TAD soils were not suppressive to $R$. solani. Given that $R$. solani did not adversely affect population densities of 2,4-DAPG producers (Tables 4 and 5 ), a possible explanation for a lack of suppressiveness to $R$. solani may be the relative insensitivity of this fungus to $2,4-\mathrm{DAPG}$ (20). Secondly, the $0.5 \%$ inoculum rate used in our experiments was high, which may have overwhelmed the system and may explain the failure to detect suppressiveness to $R$. solani. Furthermore, fungi can change patterns of bacterial gene expression (16) and more specifically interfere with the production of 2,4-DAPG $(15,25)$. The suppressiveness of Dutch TAD soils to pathogens other than $G$. graminis and their interaction with 2,4-DAPGproducing Pseudomonas spp. are currently under investigation.

\section{ACKNOWLEDGMENTS}

This research was financially supported by CAPES, Brazil (Project nr.1515/96-9). We thank L. S. Thomashow for providing E. coli S17 $\lambda$ pir containing the mini-Tn5lacZ element in plasmid pUT, P. J. G. M. de Wit for critically reading the manuscript and for valuable suggestions, and $\mathrm{C}$. F. Geerds for technical assistance.

\section{LITERATURE CITED}

1. Asher, M. J. C., and Shipton, P. J. eds. 1981. Biology and Control of Take-All. Academic Press, New York.

2. Aberra, M. B., Seah, S., and Sivasithamparam, K. 1998. Suppression of the take-all fungus (Gaeumannomyces graminis var. tritici) by a sterile red fungus through induced resistance in wheat (Triticum aestivum) seedling roots. Soil Biol. Biochem. 30:1457-1461.

3. Bangera, M. G., and Thomashow, L. S. 1996. Characterization of a genomic locus required for synthesis of the antibiotic 2,4-diacetylphloroglucinol by the biological control agent Pseudomonas fluorescens Q2-87. Mol. Plant-Microbe Interact. 9:83-90.

4. Barnett, S. J., Singleton, I., and Ryder, M. 1999. Spatial variation in populations of Pseudomonas corrugata 2140 and pseudomonads on take-all diseased and healthy roots systems of wheat. Soil Biol. Biochem. 31:633-636.

5. Bonsall, R. F., Weller, D. M., and Thomashow, L. S. 1997. Quantification of 2,4-diacetylphloroglucinol produced by fluorescent Pseudomonas sp. in vitro and in the rhizosphere of wheat. Appl. Environ. Microbiol. 63:951-955. 
6. Brown, M. E. 1981. Microbiology of roots infected with the take-all fungus (Gaeumannomyces graminis var. tritici) in phased sequences of winter wheat. Soil Biol. Biochem. 13:285-291.

7. Carroll, H., Moënne-Loccoz, Y., Dowling, D. N., and O'Gara, F. 1995. Mutational disruption of the biosynthesis genes coding for the antifungal metabolite 2,4-diacetylphloroglucinol does not influence the ecological fitness of Pseudomonas fluorescens F113 in the rhizosphere of sugarbeets. Appl. Environ. Microbiol. 61:3002-3007.

8. Charigkapakorn, N., and Sivasithamparam, K. 1987. Changes in the composition and population of fluorescent pseudomonads in wheat roots inoculated with successive generations of root-piece inoculum of the take-all fungus. Phytopathology 77:1002-1007.

9. Cook, R. J. 1985. Biological control of plant pathogens, with special reference to the take-all fungus in suppressive soils. Taiwan Agric. Res. Inst. Plant Prot. Bull. 27:179-198.

10. Cook, R. J., and Baker, K. F. 1983. The Nature and Practice of Biological Control of Plant Pathogens. The American Phytopathological Society, St. Paul, MN.

11. Cook, R. J., and Rovira, A. D. 1976. The role of bacteria in the biological control of Gaeumannomyces graminis by suppressive soils. Soil Biol. Biochem. 8:269-273.

12. Davies, K. G., Fargette, M., Balla, G., Daudi, A., Dupponnois, R., Gowen, S. R., Mateille, T., Phillips, M. S., Sawadogo, S., Trivino, C., Vouyoukalou, E., and Trudgill, D. L. 2001. Cuticle heterogeneity as exhibited by Pasteuria spore attachment is not linked to the phylogeny of parthenogenetic root-knot nematodes (Meloidogyne spp.). Parasitology 122:111-120.

13. Deacon, J. W. 1976. Biological control of the take-all fungus, $G$. graminis, by $P$. radicicola and similar fungi. Soil Biol. Biochem. 8:275283.

14. De Lorenzo, V., Herrero, M., Jakubzik, U., and Timmis, K. N. 1990. Mini-Tn5 transposon derivatives for insertion mutagenesis, promoter probing, and chromosomal insertion of cloned DNA in Gram-negative eubacteria. J. Bacteriol. 172:6568-6572.

15. Duffy, B. K., and Défago, G. 1997. Zinc improves biocontrol of Fusarium crown and root rot of tomato by Pseudomonas fluorescens and represses the production of pathogen metabolites inhibitory to bacterial antibiotic biosynthesis. Phytopathology 87:1250-1257.

16. Fedi, S., Tola, E., Moënne-Loccoz, Y., Dowling, D. N., Smith, L. M., and O'Gara, F. 1997. Evidence for signaling between the phytopathogenic fungus Pythium ultimum and Pseudomonas fluorescens: P. ultimum represses the expression of genes in $P$. fluorescens F113, resulting in altered ecological fitness. Appl. Environ. Microbiol. 63:4261-4266.

17. Gerlagh, M. 1968. Introduction of Ophiobolus graminis into new polders and its decline. Neth. J. Plant Pathol. 74:1-97.

18. Hampl, V., Pavlicek, A., and Flegr, J. 2001. Construction and bootstrap analysis of DNA fingerprinting-based phylogenetic trees with the freeware program FreeTree: Application to trichomonad parasites. Int. J. Syst. Evol. Microbiol. 51:731-735.

19. Hornby, D. 1983. Suppressive soils. Annu. Rev. Phytopathol. 21:65-85.

20. Keel, C., Schnider, U., Maurhofer, M., Voisard, C., Laville, J., Burger, U., Wirthner, P., Haas, D., and Défago, G. 1992. Suppression of root diseases by Pseudomonas fluorescens CHA0: Importance of the secondary metabolite 2,4-diacetylphloroglucinol. Mol. Plant-Microbe Interact. 5:4-13.

21. Keel, C., Weller, D. M., Natsch, A., Défago, G., Cook, R. J., and Thomashow, L. S. 1996. Conservation of the 2,4-diacetylphloroglucinol biosynthesis locus among fluorescent Pseudomonas strains from diverse geographic locations. Appl. Environ. Microbiol. 62:552-563.

22. Mazzola, M., Cook, R. J., Thomashow, L. S., Weller, D. M., and Pierson, L.S., III. 1992. Contribution of phenazine antibiotic biosynthesis to the ecological competence of fluorescent pseudomonads in soil habitats. Appl. Environ. Microbiol. 58:2616-2624.

23. Mazzola, M., and Gu, Y.-H. 2000. Impact of wheat cultivation on microbial communities from replant soils and apple growth in greenhouse trials. Phytopathology 90:114-119.

24. McSpadden-Gardener, B. B., Schroeder, K. L., Kalloger, S. E., Raaijmakers, J. M., Thomashow, L. S., and Weller, D. M. 2000. Genotypic and phenotypic diversity of phlD-containing Pseudomonas strains isolated from the rhizosphere of wheat. Appl. Environ. Microbiol.
66:1939-1946

25. Notz, R., Maurhofer, M., Schnider-Keel, U., Duffy, B., Haas, D., and Défago, G. 2001. Biotic factors affecting expression of the 2,4-diacetylphloroglucinol biosynthesis gene phlA in Pseudomonas fluorescens biocontrol strain CHA0 in the rhizosphere. Phytopathology 91:873-881.

26. Page, R. D. M. 1996. TREEVIEW: An application to display phylogenetic trees on personal computers. Comput. Appl. Biosci. 12:357-358.

27. Raaijmakers, J. M., Bonsall, R. F., and Weller, D. M. 1999. Effect of population density of Pseudomonas fluorescens on production of 2,4diacetylphloroglucinol in the rhizosphere of wheat. Phytopathology 89:470-475.

28. Raaijmakers, J. M., and Weller, D. M. 1998. Natural plant protection by 2,4-diacetylphloroglucinol-producing Pseudomonas spp. in take-all decline soils. Mol. Plant-Microbe Interact. 11:144-152.

29. Raaijmakers, J. M., and Weller, D. M. 2001. Exploiting genotypic diversity of 2,4-diacetylphloroglucinol-producing Pseudomonas spp.: Characterization of superior root-colonizing P. fluorescens strain Q8r196. Appl. Environ. Microbiol. 67:2545-2554.

30. Raaijmakers, J. M., Weller, D. M., and Thomashow, L. S. 1997. Frequency of antibiotic-producing Pseudomonas spp. in natural environments. Appl. Environ. Microbiol. 63:881-887.

31. Sambrook, J., and Russel, D. W. 2001. Molecular Cloning: A Laboratory Manual. 3rd ed. Cold Spring Harbor Laboratory, Cold Spring Harbor, NY.

32. Sarniguet, A., Lucas, P., Lucas, M., and Samson, R. 1992. Soil conduciveness to take-all of wheat: Influence of the nitrogen fertilizers on the structure of populations of fluorescent pseudomonads. Plant Soil 145:2936

33. Sharifi-Tehrani, A., Zala, M., Natsch, A., Moënne-Loccoz, Y., and Défago, G. 1988. Biocontrol of soil-borne fungal diseases by 2,4-diacetylphloroglucinol-producing pseudomonads with different restriction profiles of amplified 16S rDNA. Eur. J. Plant Pathol. 104:631-643.

34. Shipton, P. J. 1975. Take-all decline during cereal monoculture. Pages 137-144 in: Biology and Control of Soil-Borne Plant Pathogens. G. W. Bruehl, ed. The American Phytopathological Society, St. Paul, MN.

35. Simon, A., and Ridge, E. H. 1974. The use of ampicillin in a simplified selective medium for the isolation of fluorescent pseudomonads. J. Appl. Bacteriol. 37:459-460.

36. Smiley, R. W. 1978. Colonization of wheat roots by Gaeumannomyces graminis var. tritici inhibited by specific soils, microorganisms and ammonium-nitrogen. Soil Biol. Biochem. 10:175-179.

37. Smith, K. P., Handelsman, J., and Goodman, R. M. 1999. Genetic basis in plants for interactions with disease-suppressive bacteria. Proc. Natl. Acad. Sci. USA 96:4786-4790.

38. Thomashow, L. S., and Weller, D. M. 1996. Current concepts in the use of introduced bacteria for biological disease control: Mechanisms and antifungal metabolites. Pages 187-236 in: Plant-Microbe Interactions, Vol. 1. G. Stacey and N. T. Keen, eds. Chapman and Hall, New York.

39. Vojinovic, Z. D. 1972. Biological antagonism as the cause of decline of Ophiobolus graminis Sacc. in prolonged wheat monoculture. J. Sci. Agric. Res. 25:31-41.

40. Wang, C., Ramette, A., Punjasamarnwong, P., Zala, M., Natsch, A., Moënne-Loccoz, Y., and Défago, G. 2001. Cosmopolitan distribution of phlD-containing dicotyledonous crop-associated biocontrol pseudomonads of worldwide origin. FEMS Microbiol. Ecol. 37:105-116.

41. Weller, D. M., Howie, W. J., and Cook, R. J. 1988. Relationship between in vitro inhibition of Gaeumannomyces graminis var. tritici and suppression of take-all of wheat by fluorescent pseudomonads. Phytopathology 78:1094-1100.

42. Wildermuth, G. B. 1980. Suppression of take-all by some Australian soils. Austral. J. Agric. Res. 31:251-258.

43. Wildermuth, G. B. 1982. Soils suppressive to Gaeumannomyces graminis var. tritici: Effects on other fungi. Soil Biol. Biochem. 14:561-567.

44. Wong, P. T. W., and Baker, R. 1984. Suppression of wheat take-all and Ophiobolus patch by fluorescent pseudomonads from a Fusariumsuppressive soil. Soil Biol. Biochem. 16:397-403.

45. Zogg, H., and Jaggi, W. 1974. Studies on the biological soil disinfection. VII. Contribution to the take-all decline (Gaeumannomyces graminis) imitated by means of laboratory trials and some of its possible mechanisms. Phytopathol. Z. 81:160-169. 